\title{
Perawatan Kayu Secara Tradisional pada Masyarakat Bugis-Makassar dan Toraja
}

\author{
Dewi Susanti \\ Balai Pelestarian Cagar Budaya Makassar \\ dewisusantiarkeo_02@yahoo.com
}

\begin{abstract}
Abstrak : Kegiatan perawatan kayu yang selama ini dilakukan sering tergantung pada penggunaan bahan kimia (modern) dan jarang memperhatikan tradisi-tradisi yang masih berlaku dalam masyarakat, yang telah diwariskan dari generasi satu ke generasi lainnya. Kearifan lokal yang dimiliki oleh masyarakat kita sangat kaya, salah satunya mengenai perawatan bangunan kayu. Kearifan lokal yang dimiliki oleh masyarakat di wilayah Kabupaten Bone, Tana Toraja dan Toraja Utara serta Kabupaten Jeneponto perlu dilestarikan, mengingat bahwa metode yang dilakukan oleh masyarakat pada wilayah tersebut sangat efektif untuk diterapkan pada kondisi sekarang dan yang akan datang. Metode yang dilakukan dan bahan yang digunakan dapat ditemukan pada bangunan-bangunan rumah adat yang ada pada keempat kabupaten tersebut dan sampai saat ini kondisi bangunan masih sangat bagus.

Perawatan yang dilakukan cukup sederhana baik dari segi metode maupun bahan-bahan yang digunakan. Hal ini dapat kita lihat dan temukan pada kehidupan masyarakat yang ada di Kabupaten Bone. Masyarakat yang bermukim di daerah pedalaman melakukan pengawetan kayu yang akan digunakan pada bangunan dengan cara merendam pada hilir-hilir sungai, sedangkan masyarakat yang bermukim di sekitar pesisir (daerah pantai) melakukan pengawetan dengan cara merendam pada air laut. Perendaman dengan air laut hanya dilakukan pada kayu yang masih tergolong muda, sedangkan kayu yang tua hanya ditaburi garam dapur. Hal ini dilakukan disaat kayu dalam proses pengeringan. Masyarakat Toraja pada umumnya melakukan pengawetan dengan cara merendam dalam lumpur, sedangkan masyarakat di Kabupaten Jeneponto melakukan pengawetan dengan menggunakan bahan-bahan yang terdiri dari kulit luar pohon petai cina, kulit luar pohon syzygium atau yang lebih dikenal dengan nama pohon coppeng (nama lokal), dan daun sirsak. Untuk melakukan pembuktian secara ilmiah mengenai bahan-bahan dan metode yang digunakan tersebut maka perlu dilakukan kajian yang lebih dalam lagi.
\end{abstract}

\section{Kata Kunci: Kearifan lokal, Perawatan, Kayu, dan Masyarakat}

Abstrak : Wood maintenance is usually carried out by application of modern chemical material and never pays attention to the living traditions that have been passed on from generations. We have very rich local wisdoms, making wooden structure's maintenance as one of them. A local wisdom owned by the community in Bone, Toraja and Toraja Utara as well as Jeneponto Regency has a very effective maintenancemethod to be applied in present and future condition. The method and material used can be found in traditional customary houses on those four regencies, while the positive impact can be seen on the good condition of the houses. Therefore, we need to protect and preserve this traditional method.

Maintenance conducted has a very simple method and easily found materials. The secluded community in Bone has preserved the woods by soaking young wood in salt water and sprinkling old wood with salt when it is in drying process. The Toraja community preserves the woods by soaking them in mud, while the Jeneponto community preserves the woods using materials such as outer skin of Chinese petai tree, syzygium(locally known as coppeng), and leaf of soursop. Further study is needed to scientifically prove the efficacy of these methods.

Keywords: Local Wisdom, Maintenance, Wood, and Community

\section{Latar Belakang}

Berbagai persoalan yang dihadapi saat ini dalam perawatan bangunan cagar budaya, khususnya yang berbahan kayu disebabkan oleh kurangnya data dan kajian yang dimiliki. Data mengenai perawatan secara tradisonal yang masih berlanjut dalam masyarakat sering disepelekan atau tidak diperhatikan. Perawatan yang dilakukan lebih mengandalkan bahan-bahan modern (bahan kimia). Namun penggunaan bahan kimia terhadap bangunan kayu tidak menutup kemungkinan dapat menimbulkan terjadinya kerusakan lebih lanjut. Kajian mengenai perawatan bangunan kayu secara tradisional dilakukan oleh tim 
dari BPCB Makassar pada tahun 2013. Tujuan yang ingin dicapai adalah untuk mengurangi penggunaan bahan kimia dalam penanganan cagar budaya berbahan kayu. Pada awalnya ide untuk melakukan kajian bangunan kayu terinspirasi dari bangunanbangunan yang masih dapat kita temukan di beberapa wilayah Indonesia, khususnya di wilayah Toraja, Jeneponto, dan Bone. Di wilayah tersebut kita masih dapat menemukan beberapa bangunan kayu yang sudah berusia ratusan tahun dan masyarakat yang melakukan perawatan kayu dengan bahan dan metode tradisional. Langkah yang dilakukan dalam kajian ini yaitu, pertama-tama melakukan klasifikasi mengenai wilayah-wilayah mana yang masih tetap mempertahankan kearifan lokal dalam perawatan kayu. Kemudian membuat perencanaan mengenai pelaksanaan kajian, membuat jadwal kajian, dan dilanjutkan dengan pelaksanaan kajian di lokasilokasi tersebut. Data dan informasi yang akan diambil dalam kajian ini cukup banyak, sehingga tim kajian dibagi menjadi beberapa tim kecil agar waktu dapat dimanfaatkan secara optimal. Pengumpulan data dan informasi di lapangan dilakukan dengan wawancara kepada masyarakat yang dianggap mengerti dan memahami tentang perawatan bangunan kayu. Masyarakat yang diwawancarai adalah orang yang dituakan di kampung atau wilayah tersebut, tukang kayu, pemilik rumah atau bangunan, dan masyarakat biasa (masyarakat yang bermukim di wilayah tersebut).

Daerah yang menjadi sasaran kajian perawatan bangunan kayu secara tradisional adalah Kabupaten Bone, Jeneponto, Toraja Utara dan Tana Toraja. Pemilihan lokasi ini berdasarkan pada asumsi bahwa daerah-daerah ini memiliki kekayaan tinggalan cagar budaya yang terbuat dari kayu, selain itu kekayaan pengetahuan masyarakat di wilayah tersebut mengenai perawatan bangunan kayu secara tradisonal cukup bervariasi, serta daerah-daerah tersebut dianggap mewakili wilayah pengunungan, pedalaman, dan pesisir. Hal yang sangat menarik dalam kajian ini adalah bahan dan metode yang digunakan sangat tergantung pada alam atau lingkungan mereka.
Metode yang digunakan oleh masyarakat di Kabupaten Bone adalah dengan melakukan perendaman kayu pada hilir-hilir sungai, perendaman pada air laut, dan menaburkan garam dapur (Natrium klorida/NaCL). Di daerah Toraja perawatan kayu dilakukan dengan cara perendaman di dalam lumpur, sedangkan di daerah Jeneponto menggunakan kulit luar pohon petai cina, kulit luar pohon syzygium atau yang lebih dikenal dengan nama pohon coppeng (nama lokal), dan daun sirsak. Kearifan lokal yang dimiliki oleh masyarakat ini perlu dikaji lebih lanjut, dan dalam kegiatan kajian ini akan dilakukan analisisanalisis mengenai bahan-bahan yang digunakan dalam perawatan kayu tersebut.

\section{Prosedur}

Umumnya sebuah studi ilmiah secara metodologis dilakukan dengan menyusun kerangka kerja yang mengikuti prosedur standar, meliputi; pengumpulan, interpretasi, dan analisis data. Pada dasarnya kegiatan ini sangat bergantung pada kondisi lapangan.

Pengumpulan data adalah tahap pertama yang dilakukan, yaitu berupa kajian pustaka dengan cara mengumpulkan berbagailiteraturdariberbagaisumber seperti buku, majalah, artikel ataupun laporan-laporan hasil penelitian mengenai jenis-jenis kayu yang ada di Kabupaten Bone, Jeneponto, Toraja Utara, serta Tana Toraja dan sekitarnya. Pengumpulan data lapangan dilakukan dengan melakukan wawancara kepada beberapa tokoh masyarakat dan pada masyarakatnya sendiri yang dianggap cukup banyak mengerti dan paham mengenai perawatan bangunan kayu secara tradisional. Selain itu, untuk melengkapi informasi yang telah dikumpulkan dan untuk kepentingan analisis, maka dilakukan pengambilan sampel bahan baku bangunan (sampel kayu), air, tanah, maupun jenis-jenis tumbuhan (tanaman) yang digunakan dalam perawatan kayu.

Observasi dengan pencatatan adalah kegiatan yang dilakukan dengan maksud untuk mengumpulkan data berupa kondisi umum lokasi penelitian, bentuk kearifan masyarakat dalam melakukan perawatan bangunan kayu baik dari segi bahan maupun metode, 
serta melakukan pengumpulan data mengenai jenisjenis kayu yang digunakan pada bangunan.

Pemotretan dilakukan untuk merekam secara visual kondisi lingkungan, jenis bahan-bahan yang digunakan dalam melalukan perawatan bangunan kayu, jenis kayu, serta dalam proses wawancara.

Wawancara merupakan kegiatan untuk mengumpulkan data administrasi lokal yang tidak diperoleh pada studi pustaka dan juga mengumpulkan data informal terutama yang berhubungan dengan perawatan bangunan kayu.

Tahap selanjutnya adalah analisis data, yang merupakan langkah sangat penting dalam melakukan sebuah penelitian atau kajian, karena pada tahap inilah semua data yang diperoleh baik dari lapangan ataupun dari hasil penelusuran literatur akan diformulasikan. Adapun analisis yang dilakukan terhadap sampel, baik sampel kayu maupun sampel bahan yang digunakan dalam melakukan perawatan kayu adalah analisis secara fisik dengan tujuan untuk mengetahui unsur-unsur fisikal atau kemikal yang terkandung pada bahan (kayu) dan bahan-bahan yang digunakan dalam melakukan perawatan. Analisis ini dilakukan di laboratorium BPCB Makassar dan laboratorium Balai Industri Makassar.

\section{Gambaran Umum Wilayah Kabupaten Bone}

Secara topografis Kabupaten Bone terdiri atas daerah pantai, dataran, dan pegunungan. Daerah pantai meliputi 9 kecamatan yaitu Kecamatan Cenrana, Tellu SiantingE, Awangpone, Tanete Riattang Timur, SibuluE, Mare, Tonra, Salomekko, dan Kajuara. Karena luas lahan persawahan yang mencapai $455.600 \mathrm{Ha}$, Kabupaten Bone ditetapkan sebagai daerah penghasil beras di Provinsi Sulawesi Selatan. Sebagian besar mata pencarian penduduk adalah petani dan nelayan.

\section{Tana Toraja}

Secara administratif wilayah Tana Toraja terbagi menjadi dua wilayah pemerintahan kabupaten, yaitu Kabupaten Tana Toraja dengan ibukota Makale dan Kabupaten Toraja Utara dengan ibukota Rantepao. Kabupaten Toraja Utara dibentuk berdasarkan Undang-Undang Nomor 28 Tahun 2008 yang disahkan pada Juli 2008. Namun data statistik pendukung untuk Kabupaten Toraja Utara belum tersedia hingga saat ini, sehingga penyajian data laporan yang berhubungan dengan kabupaten baru ini masih menggunakan data lama sebelum pemekaran.

Secara geografis Kabupaten Tana Toraja terletak di sebelah utara ibukota Provinsi Sulawesi Selatan (Makassar) pada koordinat antara $2^{\circ}-3^{\circ}$ LS dan $119^{\circ}$ - 120 BT, dengan luas wilayah sekitar 3.205,77 $\mathrm{Km}^{2}$. Batas-batas Kabupaten Toraja Utara dan Kabupaten Tana Toraja adalah sebelah utara berbatasan dengan Kabupaten Luwu, Kabupaten Mamuju, dan Kabupaten Mamasa. Sebelah timur berbatasan dengan Kabupaten Luwu, sebelah selatan dengan Kabupaten Enrekang, dan Kabupaten Pinrang. Sebelah barat dengan Kabupaten Polmas. Secara topografis Tana Toraja berada pada wilayah pegunungan, berbukit, dan berlembah.

\section{Kabupaten Jeneponto}

Kabupaten Jeneponto termasuk dalam daerah tingkat dua di Provinsi Sulawesi Selatan. Secara astronomis terletak pada $5^{\circ} 16^{\prime} 13^{\prime \prime}$ - 5 $5^{\circ} 39^{\prime} 35^{\prime \prime}$ LS dan $12^{\circ} 40^{\prime} 19^{\prime \prime}-12^{\circ} 7^{\prime} 31^{\prime \prime}$ BT. Kabupaten Jeneponto memiliki luas wilayah $74.979 \mathrm{Ha}$. Kabupaten ini berbatasan dengan daerah-daerah lain, yaitu sebelah utara berbatasan dengan Kabupaten Gowa dan Kabupaten Takalar. Sebelah selatan berbatasan dengan Laut Flores, sebelah timur berbatasan dengan Kabupaten Bantaeng, dan sebelah barat berbatasan dengan Kabupaten Takalar. Kabupaten ini berjarak $\pm 90 \mathrm{Km}$ dari Kota Makassar. Kabupaten Jeneponto biasa juga disebut ButtaTuratea.

\section{Perawatan Kayu}

\section{Masyarakat Kabupaten Bone}

Masyarakat Bone lebih cenderung memanfaatkan lingkungan sebagai media untuk melakukan pengawetan kayu yang akan digunakan pada bangunan. Di Desa Naga Uleng, Kecamatan Cenrana, Kabupaten Bone, masyarakat terlebih dahulu merendam kayu-kayu yang akan digunakan untuk pembangunan rumah pada hilir-hilir sungai. Hal tersebut dilakukan dengan tujuan agar kayu lebih 


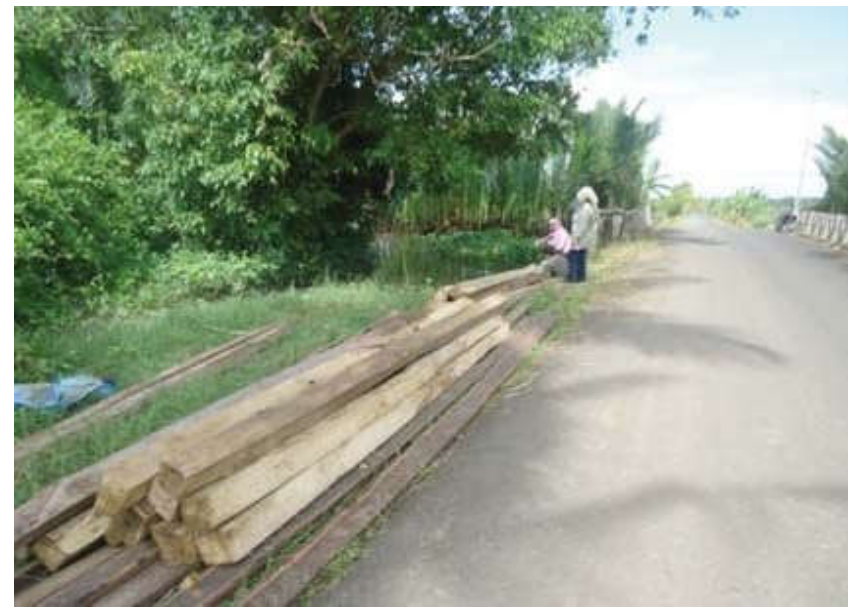

Foto 1. Aktivitas perendaman kayu pada hilir-hilir sungai

kuat dan tahan terhadap serangan rayap dan bubuk kering.

Dari hasil pengumpulan data yang dilakukan pada saat pelaksanaan kajian perawatan bangunan kayu secara tradisional ini, dapat diketahui bahwa metode dan bahan-bahan yang digunakan oleh masyarakat pada setiap daerah itu berbeda, misalnya metode perawatan (pengawetan) yang dilakukan oleh masyarakat yang bermukim di daerah pesisir (pantai) tepatnya di Kecamatan Tanete Riantang Timur. Perawatan yang dilakukan oleh masyarakat di daerah ini juga sangat menarik, yaitu dengan melakukan perendaman di dalam air laut. Namun tidak semua kayu yang akan mereka gunakan direndam dalam air laut. Perendaman ini hanya dilakukan pada kayukayu yang masih tergolong muda, sedangkan pada kayu yang umurnya cukup tua tidak direndam, tetapi hanya dikeringkan. Dalam proses pengeringan, kayukayu tersebut ditaburi garam dapur dengan tujuan untuk menghindari serangan serangga dan semut.

\section{Masyarakat Tana Toraja}

Sebagian besar masyarakat meyakini bahwa semakin lama direndam maka kayu tersebut akan semakin awet. Maka dari itu masyarakat Toraja melakukan pengawetan kayu dengan cara merendam di dalam lumpur minimal 3 bulan, bahkan ada yang sampai satu tahun. Tujuan dari perendaman ini adalah agar kayu yang akan digunakan dalam pembuatan tongkonan atau rumah adat lebih tahan lama dan terhindar dari serangan rayap maupun serangga lainnya. Di salah satu daerah di Toraja Utara masih mempertahankan kearifan lokal yang berdasarkan pada ajaran aluk to dolo yang mengatakan bahwa hal pertama yang harus diperhatikan dimulai dari proses penebangan kayu yang akan digunakan pada tongkonan.

Pada ajaran aluk to dolo pengambilan bahan kayu dari hutan adat dilakukan secara acak dan tebang pilih. Selain itu, hal sangat penting yang harus diperhatikan yaitu posisi bulan harus tepat dalam posisi bulan bongi, dimana bulan selalu muncul baik pada malam maupun siang hari. Setelah bahan tongkonan ditebang maka akan dilakukan pengawetan dengan cara merendam kayu tersebut di dalam lumpur dengan tujuan untuk mencegah kerusakan dari ancaman mikroorganisme.

\section{Masyarakat Kabupaten Jeneponto}

Perawatan kayu yang dilakukan oleh masyarakat Jeneponto cukup sederhana dan bahan-bahan yang digunakan sangat mudah ditemukan di wilayah tersebut. Hal ini karena masyarakat cenderung melakukan pengawetan bangunan kayu dengan memanfaatkan bahan-bahan yang ada di lingkungan sekitar tempat tinggal mereka. Bahan yang digunakan dalam melakukan perawatan bangunan kayu terdiri atas kulit luar pohon petai cina (nama lokal pohon tammate) dicampur dengan kulit luar pohon Syzygium Sp. (nama lokal pohon coppeng), kemudian ditambah sedikit daun sirsak (nama lokal daun srikayalannona muricata).

Ketiga bahan tersebut disimpan dalam satu wadah (panci), kemudian direbus secara bersamaan dan dibiarkan mendidih sampai beberapa menit, kemudian bahan tersebut diangkat dan didiamkan sampai dingin. Bahan siap digunakan dengan cara dioleskan pada kayu atau bagian dari bangunan yang terbuat dari kayu. Mengacu dari hasil pengumpulan data yang dilakukan saat pelaksanaan kajian ini, maka diperoleh data dan informasi bahwa bahan tersebut sangat efektif untuk melindungi kayu, baik dari segi pewarnaan maupun dari serangan rayap, serta bubuk kayu kering. 


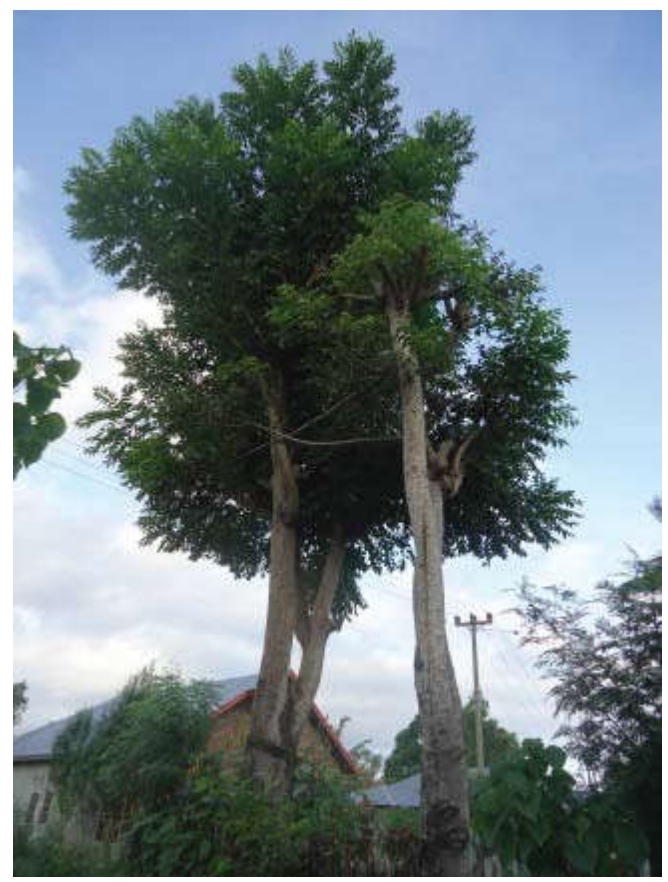

Foto 2. Pohon petai cina (pohon tammate)

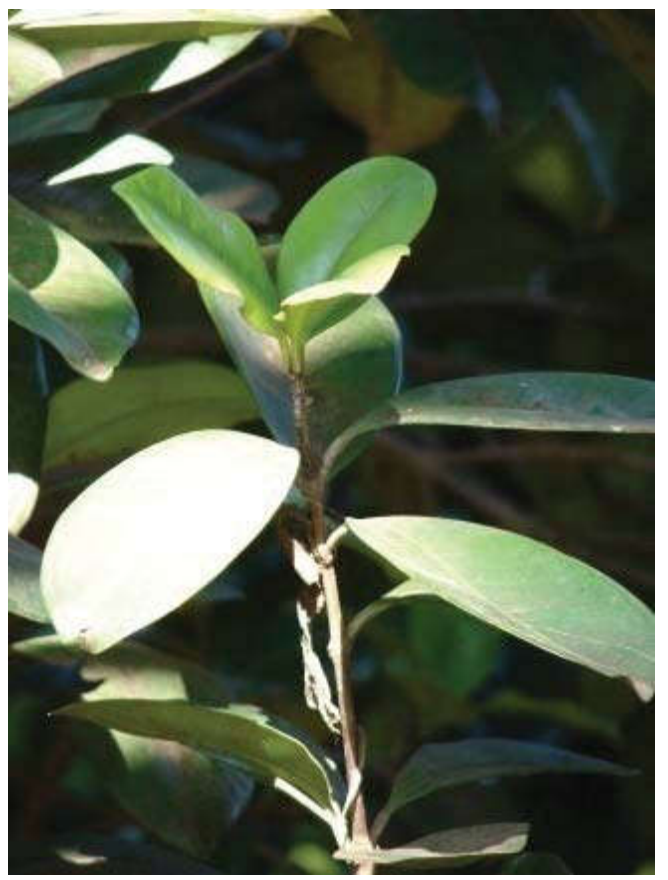

Foto 3. Pohon Syzygium Sp (pohon coppeng)

\section{Analisis Laboratorium}

Berdasarkan informasi yang diperoleh mengenai bahan-bahan yang digunakan dalam perawatan kayu di Kabupaten Jeneponto, maka kami mencoba melakukan analisis laboratorium dengan tujuan untuk mengetahui kandungan dan senyawa kimianya. Namun sebelum sampel dianalisis, terlebih dahulu dilakukan preparasi sampel dengan tahapan persiapan sebagai berikut:

1. Kulit luar pohon petai cina dan pohon Syzygium Sp. (nama lokal; pohon coppeng) diambil kemudian dikeringkan hingga kering tanur.

2. Setelah kulit pohon tersebut kering, masingmasing sampel ditimbang sebanyak 10 gram. Selanjutnya, memanaskan air sebanyak $500 \mathrm{ml}$ dalam beacker glass hingga mendidih, kemudian sampel dimasukkan. Pemanasan ini dilakukan kurang lebih selama 1 jam, hal ini dimaksudkan untuk melarutkan kandungan-kandungan kimia dalam kulit pohon tersebut.

3. Menyaring sampel untuk memisahkan larutan dan ekstraknya menggunakan kertas saring (filter papers) nomor 41 dan sampel siap untuk dianalisis.

Foto 7, 8, dan 9 menunjukkan proses atau langkah dalam melakukan analisis laboratorium. Foto 7 menunjukkan persiapan wadah untuk melakukan penyaringan larutan yang telah dipanaskan; Foto 8 menunjukkan proses penyaringan larutan yang telah dipanaskan; dan Foto 9 menunjukkan larutan yang telah dipisahkan dengan ekstraknya dan telah siap untuk dianalisis.

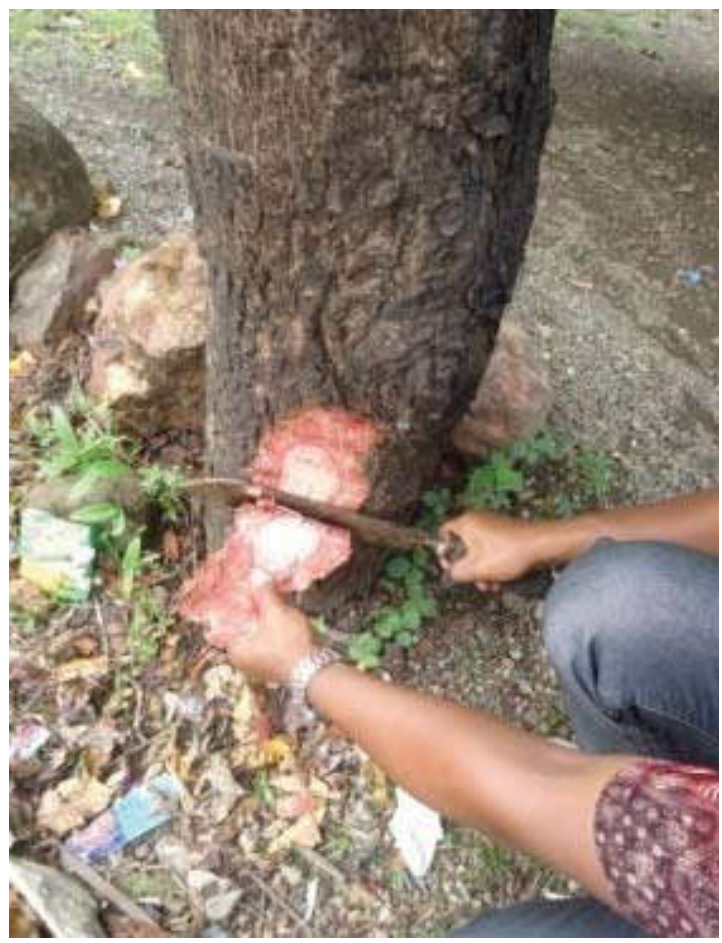

Foto 4. Pengambilan sampel kulit pohon petai cina 


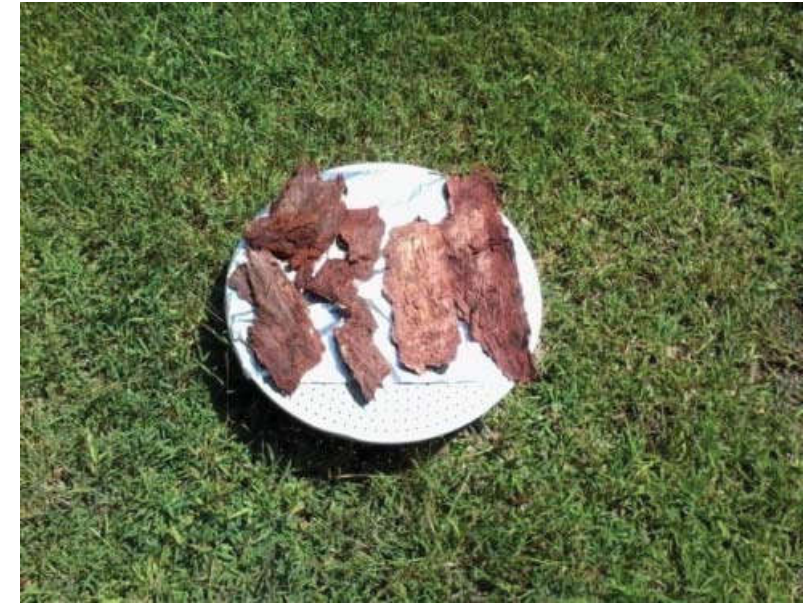

Foto 5. Sampel kulit pohon petai cina

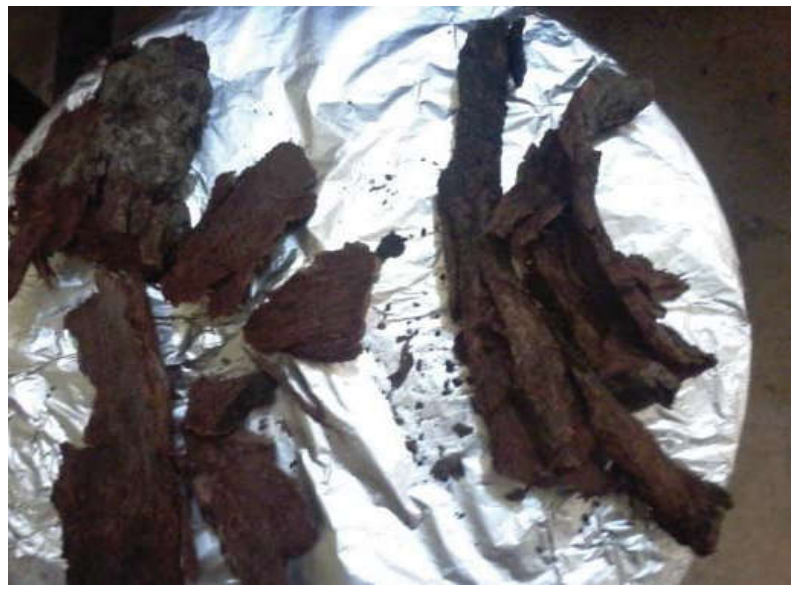

Foto 6. Sampel kulit pohon coppeng

Berdasarkan hasil analisis sampel-sampel yang dilakukan di laboratorium, maka diperoleh data seperti pada Tabel 1.

Dari tabel di atas dapat diketahui bahwa hasil analisis kadar unsur kimia dari beberapa sampel uji tanah di daerah Tana Toraja dan Toraja Utara menunjukkan bahwa unsur yang paling banyak adalah silika $\left(\mathrm{SiO}_{2}\right)$. Seperti telah diuraikan sebelumnya, masyarakat Tana Toraja dan Toraja Utara melakukan metode perawatan kayu dengan cara merendam dalam lumpur tanah. Dari hasil analisis dapat dijelaskan

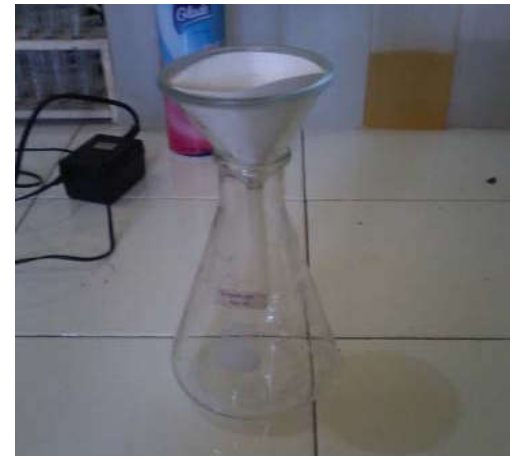

Foto 7. Erlenmeyer dan kertas saring untuk penyaringan larutan

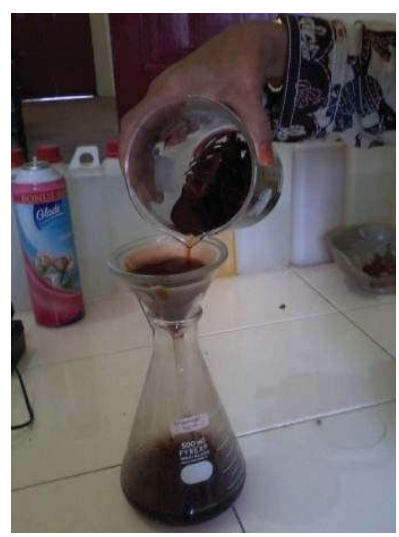

Foto 8. Proses penyaringan larutan yang telah dipanaskan

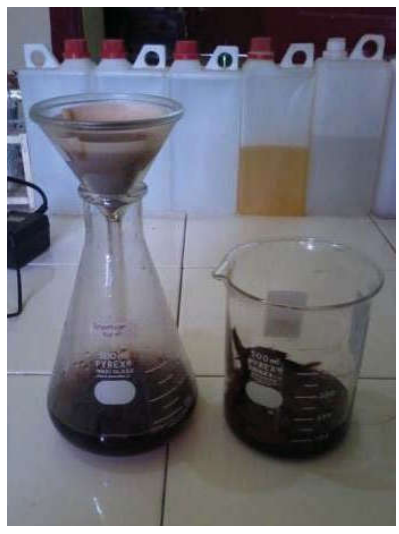

Foto 9. Larutan preparat sampel untuk dianalisis

Tabel 1. Hasil Analisis Sampel Uji Air dan Tanah

\begin{tabular}{llcccc} 
& \multicolumn{4}{c}{ Kadar Analisis Kimia (\%) } \\
No. & \multicolumn{1}{c}{ Sampel Uji } & Besi & Magnesium & Silika & Calsium \\
\hline $1 \quad$ & $(\mathrm{Fe})$ & $(\mathrm{Mg})$ & $\left(\mathrm{SiO}_{2}\right)$ & $(\mathrm{Ca})$ \\
\hline $\begin{array}{l}\text { Lumpur tanah di sekitar tongkonan RA. Kete } \\
\text { Kesu }\end{array}$ & 0,24 & 1,47 & 25,72 & 13,58 \\
\hline $\begin{array}{l}\text { Lumpur tanah di sekitar tongkonan RA. } \\
\text { Pallawa }\end{array}$ & 1,33 & 2,09 & 27,22 & 10,43
\end{tabular}




\begin{tabular}{|c|c|c|c|c|c|}
\hline 3 & $\begin{array}{l}\text { Lumpur tanah di sekitar tongkonan RA. } \\
\text { Silanan }\end{array}$ & 1,71 & 1,12 & 22,16 & 14,01 \\
\hline 4 & $\begin{array}{l}\text { Lumpur tanah di sekitar tongkonan RA. } \\
\text { Kalimbuang Bori' }\end{array}$ & 0,98 & 1,47 & 24,63 & 15,11 \\
\hline 5 & Air Sungai Cenrana Kabupaten Bone & 0,52 & 8,53 & 4,12 & 3,27 \\
\hline 6 & $\begin{array}{l}\text { Air rebusan kulit pohon petai cina, kulit } \\
\text { pohon syzyglum sp. dan daun sirsak }\end{array}$ & 1,44 & 10,06 & 2,72 & 4,19 \\
\hline 7 & $\begin{array}{l}\text { Air sumur Kel. Kelana, Kec. Tolo', Kabupaten } \\
\text { Jeneponto }\end{array}$ & 0,86 & 6,50 & 3,97 & 3,54 \\
\hline
\end{tabular}

bahwa kayu mempunyai sifat higroskopik, yaitu dapat menyerap dan melepaskan air atau kelembaban.

Hasil wawancara yang telah dilakukan kepada salah satu masyarakat di Toraja yaitu Bapak Bertina Tasik (salah seorang yang dituakan di lokasi Tongkonan Palawa generasi ke-8) mengatakan bahwa apabila kayu yang digunakan dalam sebuah bangunan dapat meyerap silika dengan baik, maka dipastikan kayu-kayu tersebut dapat bertahan atau awet secara alami. Keawetan kayu terjadi karena silika merupakan zat ekstraktif yang bersifat racun bagi jamur, kumbang bubuk kayu kering, dan rayap. Dari sampel air sungai, air rebusan kulit pohon petai cina, kulit pohon syzyglum sp., daun sirsak dan air sumur menunjukkan bahwa unsur Ca (karbonat) merupakan kandungan terbesar dalam sampel-sampel tersebut.

\section{Kesimpulan}

Masyarakat Bugis-Makassar dan Toraja memiliki kekayaan yang sangat besar mengenai pengetahuan perawatan kayu yang dilakukan secara tradisional. Bentuk kearifan lokal yang dimiliki oleh masyarakat di wilayah tersebut diwariskan secara turun menurun dan masih dapat kita temukan sampai saat ini. Penggunaan metode dan bahan yang digunakan oleh masyarakat cukup bervariasi, seperti perawatan kayu yang dilakukan oleh masyarakat Bugis di Kabupaten Bone terdiri atas dua jenis yaitu, (1) masyarakat yang bermukim di daerah pedalaman melakukan pengawetan dengan cara merendam kayukayu yang akan digunakan untuk bangunan pada hilir-hilir sungai; (2) masyarakat yang bermukim di sekitar pesisir pantai melakukan pengawetan dengan cara merendam kayu-kayu di dalam air laut, tetapi perlakuan ini hanya dilakukan pada kayu-kayu yang masih tergolong muda, sedangkan untuk kayu yang usianya dianggap tua pengawetan dilakukan dengan cara menaburkan garam dapur dalam proses pengeringan. Masyarakat Toraja secara umum melakukan pengawetan kayu dengan cara merendam dalam lumpur. Perbedaan yang ditemukan hanya pada durasi (waktu) perendaman, ada yang hanya direndam selama 3 bulan, tetapi batas maksimal perendaman yaitu sekitar satu tahun. Masyarakat Makassar khususnya di Kabupaten Jeneponto melakukan perawatan kayu dengan menggunakan air rebusan dari kulit luar pohon petai cina (nama lokal pohon tammate), kulit luar pohon Syzygium Sp. (nama lokal pohon coppeng), dan daun sirsak (nama lokal daun srikayalannona muricata). Semua kekayaan pengetahuan yang dimiliki oleh masyarakat ini perlu dijaga kelestariannya. 


\section{DAFTAR PUSTAKA}

Nur, Muh (editor). 2008. Jejak Sejarah Jeneponto. Masagena Press bekerja sama dengan Kantor Pariwisata Seni, dan Kebudayaan Kabupaten Jeneponto. Makassar

Martawijaya, Abdurrahim. 1981. Atlas Kayu Indonesia”. Pusat Penelitian dan Pengembangan Kehutanan. Bogor, Jawa Barat

Muttalib, Abdul M. 1984. Bola Soba Sejarab dan Pemugarannya. Peninggalan Sejarah dan Purbakala Sulawesi Selatan. Ujung Pandang

Munandar, Aris. 2006. Kerusakan dan Pelapukan Material. Balai Konservasi Peninggalan Borobudur. Magelang

Sveha, G. Vogel Jilid 1, Kimia Analisis Kualitatif Anorganik http://www.deptan.go.id/pesantren/ditbuah/ Komoditas/Sentra/kabupaten_jeneponto. htm. diakses 12 juli 2013 pukul 23.40 wita http://lontarasakti.blogspot.com/2009/11/potensiict-jeneponto.html. diakses tanggal 12 juli 2013 pukul 00.30 wita

http://www.iannnews.com/ensiklopedia. php? page $=$ tempat $\&$ prov $=9 \& \mathrm{id}=405$. diakses 12 juli 2013 pukul 02.00 wita

www.iannnews.com. Diakses tanggal 13 juli 2013 pukul 12.30 wita

www.deptan.go.id. diakses tanggal 15 juli 2013 pukul 02.00 wita 